\title{
Effects of Self-Esteem on the Associations Between Infertility-Related Stress and Psychological Distress Among Infertile Chinese Women: A Cross-Sectional Study
}

\author{
ChunYing Cui ${ }^{1}$ \\ Lie Wang' \\ XiaoXi Wang $\mathbb{D}^{2}$ \\ 'Department of Social Medicine, School \\ of Public Health, China Medical \\ University, Shenyang North New Area, \\ Shenyang, Liaoning, I 10122, People's \\ Republic of China; ${ }^{2}$ Medical Basic \\ Experimental Teaching Center, China \\ Medical University, Shenyang North New \\ Area, Shenyang, Liaoning, II0I22, \\ People's Republic of China
}

\begin{abstract}
Background: Anxiety and depression are the most common psychological causes of distress in infertile women. Our study aimed to evaluate the prevalence of depression and anxiety and investigate the effects of self-esteem on the association of infertility-related stress with depression and anxiety among infertile women.
\end{abstract}

Methods: This study was conducted between December 2017 and May 2018. Questionnaires containing Fertility Problem Inventory (FPI), Rosenberg self-esteem scale (RSES) and Hospital Anxiety and Depression Scale (HADS) were distributed among 536 female infertility patients in Shenyang, China. Hierarchical linear regression analyses were used to examine the mediating and moderating role of self-esteem. Baron and Kenny's technique, asymptotic, and resampling strategies were used to confirm the mediating role of self-esteem on the associations between infertility-related stress with depression and anxiety.

Results: The prevalence of depression and anxiety was $27.9 \%$ and $42.2 \%$ among Chinese female infertility patients, respectively. Infertility-related stress was positively associated with depression and anxiety, whereas self-esteem was negatively associated with depression and anxiety. Additionally, the effects of infertility-related stress on depression and anxiety gradually decreased along with an increase in self-esteem. Meanwhile, self-esteem partially mediated the associations between infertility-related stress with depression and anxiety.

Conclusion: A high prevalence of psychological distress was found among infertile women. Self-esteem mediated and moderated the effects of infertility-related stress on depression and anxiety. Additionally, infertility-related stress and self-esteem were associated with psychological distress, which explained why infertile women had a higher prevalence of depression and anxiety. Therefore, interventions that focus on self-esteem may be effective and should be used as a resource to combat mental health problems.

Keywords: infertility-related stress, depression, anxiety, self-esteem, infertility

\section{Background}

Infertility is a disease and social problem, which is defined by the World Health Organization (WHO) as "a disease of the reproductive system defined by the failure to achieve a clinical pregnancy after 12 months or more of regular unprotected sexual intercourse", 1 and has been found to affect approximately $10-12 \%$ of couples worldwide, ${ }^{2}$ with rates being higher (about $31.1 \%$ ) in low-income and middle-income countries. ${ }^{3}$ Among women, $1.9 \%$ suffer from primary infertility, 
while $10.5 \%$ experience secondary infertility. ${ }^{4}$ In China, relevant large-scale epidemiological studies have revealed that the prevalence of infertility varies widely, ranging from $6.7-25 \%$ among women of a reproductive age. ${ }^{5-7}$

In addition, prior studies have shown that women with infertility seem to be vulnerable to mental disorders caused by stress related to infertility, compared with males. ${ }^{8,9}$ The impact of infertility on women's mental health is profound throughout their life, and includes emotional, spiritual, sexual, and physical aspects. Moreover, infertility can result in low self-esteem, guilt and loneliness, social isolation, and even psychological stress. ${ }^{10}$ Depression and anxiety are the most common mental disorders in infertility patients. ${ }^{11}$ Studies have found that $14.7 \%$ of infertile women suffered from anxiety in an Italian population, while only $4.5 \%$ of men were affected. ${ }^{12}$ Additionally, some scholars have found increased symptom load where $10-50 \%$ of subjects reported mild to moderate depression, ${ }^{13}$ while major depression was reported in $17 \%$ of women. ${ }^{14}$ Psychological disorders in women with infertility are associated with high rates of problematic personality traits, such as neuroticism, ${ }^{15}$ and low quality of life. ${ }^{16}$ Furthermore, both depression and anxiety can cause a decrease in fertility and rate of pregnancy in patients being treated with assisted reproductive technology. ${ }^{17}$ Therefore, the early identification of influencing factors, screening high risk populations and implementing management strategies may be effective in decreasing the negative consequences caused by mental disorders in infertile females.

Research has shown that infertility-related stress significantly increases both anxiety and depression in women with infertility. ${ }^{18,19}$ Infertility-related stress refers to perceived stress from one's social networks, marital relationship, sexual domain, rejection of a childfree lifestyle, as well as the need for parenthood. ${ }^{20}$ In reality, the diagnosis of infertility in females may trigger negative thoughts concerning the importance of the rejection of a childfree lifestyle and the need for parenthood throughout their lives. In addition, it may involve feelings of stigma and social isolation from family and friends, a reduction in sexual pleasure and difficulty in discussing infertility issues with the couple, which induce a higher level of infertility-related stress. Furthermore, infertility treatment leads to heavy psychological and physical stress. Therefore, women with high levels of infertility-related stress can be inclined to suffer from mood disorders.
Although the association of both depression and anxiety with infertility-related stress have been examined among female infertility patients, ${ }^{18,19}$ the underlying causes remain unclear. Over the years, positive psychology has been used increasingly to prevent and treat mental health problems. Self-esteem is a term that reflects a person's overall evaluation or appraisal of her or his own worth, which encompasses beliefs and emotions, such as triumph, despair, pride or shame. ${ }^{21}$ Low levels of self-esteem result in a series of psychological or physical disorders. Self-esteem has been found to be negatively associated with depression among infertile couples. ${ }^{22,23}$ Additionally, other study have found that self-esteem can mediate the relationship between mindfulness and depression in the general population. ${ }^{24}$ Another study found that self-esteem moderated the negative impact of body-related shame and guilt on mental disorders among young adults. ${ }^{25}$ Therefore, self-esteem as a protective factor that can effectively buffer against the adverse negative impacts on mental health. In other words, self-esteem may ameliorate the negative effect of infertility-related stress on depression or anxiety. Therefore, our study aimed to ascertain the manner in which self-esteem may affect the associations between infertility-related stress with depression and anxiety in infertile women.

Nevertheless, the role of self-esteem on the associations between infertility-related stress with depression and anxiety has still not yet been explored among female infertility patients. Therefore, our study aimed to evaluate the prevalence of depression and anxiety and examine whether self-esteem affects associations of infertilityrelated stress with depression and anxiety in Chinese women with infertility.

\section{Methods}

\section{Study Design and Data Collection}

Our study used a cross-sectional design, and was conducted in Liaoning Province, China from December 2017 to May 2018. All participants were recruited from the Shenyang Women's and Children's Hospital. Participants included women who were diagnosed with infertility, who could communicate fluently in Chinese, and aged over 18 years of age. The exclusion criteria were women who currently suffered from other major diseases, history of psychiatric illness in the past, and cognitive impairments. All eligible participants were invited to participate in the study by their attending 
physicians. The researchers verified that the participants were well-informed on the purpose and steps involved in this study. After written informed consent was obtained, the participants were requested to complete a structured questionnaire. The minimum sample size was calculated using the formula: $\mathrm{n}=\left(\mathrm{Z}_{\alpha / 2}\right)^{2} P(1-P) / \delta^{2}$, using the constants, $\alpha=0.05$ and $Z_{\alpha / 2}=1.96 . P$ is the prevalence of depression and anxiety in Chinese infertile women, which is estimated based on the findings of prior studies. $P=0.20$ in the current study. ${ }^{26} \delta$ is tolerable error, and $\delta=0.04$ was used in the present study. A sample size of 384 participants was identified as the minimum sample size required. Overall, 548 eligible participants were included, and 536 effective responses were received $(97.8 \%)$. Five of the eligible were not able to participate due to health problems, and seven questionnaires that were not complete were excluded.

\section{Demographic and Clinical Information}

Our study collected information on the demographic variables of patients, including age, residency, educational level, income level, number of times of exercise weekly, sources of stress and life events. Residence was categorized as rural or urban. Educational level was categorized as high school or lower, junior college and bachelor degree or higher. Income was categorized as < 4000 and $\geq 4000$ yuan. Number of times of exercise weekly was categorized as $0,1-2$ and 3-4. Sources of stress was categorized as family, oneself and others (friend or colleague). Negative life events referred to whether participants experienced the death of a family member or severe illnesses in the family (eg, cancers), and it was categorized as either yes or no. We also surveyed clinical variables, including causes of infertility and past histories (pregnancy, infection, operation and infertility treatment). Causes of infertility were categorized as male factors (oligospermia, erectile dysfunction, etc.), female factors (eg, endometriosis, ovulation disorders), and unexplained reason. History of infertility treatment was defined as "yes", if participants had received assisted reproductive technologies (ART) Pregnancy history, operation history and infertility treatment history were categorized as either yes or no. If the participant had experienced sexually transmitted infections or had a history of induced abortion infection, infection history was identified as "yes".

\section{Measurement of Depression and Anxiety}

The Hospital Anxiety and Depression Scale (HADS) is one of the most commonly used instruments worldwide for assessing anxiety and depression in a clinical setting in patients with physical problems. ${ }^{27}$ The HADS is a 14 -item scale that consists of two subscales, including anxiety and depression, with seven items in each. Each of the items is scored on a Likert scale ( 0 indicates not at all and 3 indicates very much indeed). The global score in each subscale ranges from 0 to 21 . A higher score indicates higher levels of anxiety and depression. A HADS-A or HADS-D score of $\geq 8$ indicates possible depression and anxiety, and a score of $\geq 10$ indicates probable depression and anxiety. ${ }^{27}$ Yang et al (2019) speculated that the Chinese version of HADS had good psychometric properties in terms of internal reliability (Cronbach's $\alpha$ for HADS-D and HADS-A were 0.729 and 0.811 , respectively) and structural validity. ${ }^{28}$ The Cronbach's alpha coefficient for HADS was 0.840 (HADS-D: 0.693, HADS-A: 0.779).

\section{Measurement of Infertility-Related Stress}

Newton et al (1999) compiled a Fertility Problem Inventory (FPI), which aimed to measure the degree of stress associated with infertility. FPI contains five dimensions (rejection of a childfree lifestyle, social concern, sexual concern, relationship concern, the need for parenthood), and 46 items. $^{20}$ Peng et al (2011) translated FPI from English to Chinese, and reported good validity and reliability for FPI in the Chinese population. ${ }^{29}$ Each of the items is scored on a Likert scale (1 indicating "not agree", while 6 indicating "totally agree"). The global FPI score ranged from 46 to 276. A higher score indicated a higher degree of stress associated with infertility. The Chinese version of FPI produced a Cronbach's alpha value of 0.810 , in a previous study. ${ }^{29}$ In this current study, the Cronbach's $\alpha$ value for the FPI was 0.887 .

\section{Measurement of Self-Esteem}

Rosenberg (1965) developed the Rosenberg self-esteem scale (RSES), which was used to determine levels of selfesteem. ${ }^{30}$ The Chinese version was translated by Cheng et al $(1995)^{31}$ and consists of 10 items. Participants rated each item on a 4-point Likert scale (ranging from "strongly agree" to "strongly disagree"). The version used in this study has also been used in previous studies. $^{31,32}$ The Chinese version of FPI reported 
a Cronbach's alpha value of 0.830 in a previous study. ${ }^{33}$ In this study, the Cronbach's $\alpha$ value for the RSES was 0.749 .

\section{Statistical Analyses}

SPSS 22.0 was used to analyze all statistical data in this study. One-way ANOVA or independent-group $t$-tests were used to examine the difference between depression and anxiety using categorical variables. Correlations was examined using Pearson's correlation among continuous variables. Hierarchical regression analysis was used to investigate the effects of independent variables based on depression and anxiety and explore the effect of selfesteem. For model 1, all demographic and clinical variables that were significantly associated with depression or anxiety were included into the univariate analyses. Infertility-related stress was added into model 2 ; selfesteem was added as a variable into model 3 ; while the product of infertility-related stress and self-esteem was added into model 4. Self-esteem played a moderating role when the interaction was significant in the regression model. ${ }^{34}$ Asymptotic and resampling strategies developed by Preacher and Hayes, ${ }^{35}$ were used to examine the mediating role of self-esteem ( $\mathrm{a}^{*} \mathrm{~b}$ product) on the association between infertility-related stress and psychological outcomes, including depression and anxiety. The bootstrap estimate was based on 5000 bootstrap samples. The biascorrected and accelerated 95\% confidence interval (BCa $95 \% \mathrm{CI}$ ) was calculated for each $\mathrm{a} * \mathrm{~b}$ product, with a $\mathrm{BCa}$ 95\% CI excluding 0 indicated a significant mediating role.

All statistical tests were two-sided $(\alpha=0.05)$.

\section{Results}

\section{Descriptive Statistics}

Table 1 shows the demographic and infertility characteristics of subjects and the distributions of depression and anxiety. The mean age of the subjects was 32.77 years (SD $=4.42$; range, 22-47). Approximately $80 \%$ of participants lived in urban areas. Among the 536 infertile women, more than $50 \%$ had junior college or higher level of education, and $73.1 \%$ had a household monthly income level of $\geq 4000$-yuan RMB. Education level, income, sleep disorders, number of times of exercise weekly and history of infertility treatment were associated with depression $(P<0.05)$. With regard to the level of education and income, patients with a higher level of education and income had a lower score of depression. From among the participants, $315(58.8 \%)$ patients had received infertility treatment and their scores for depression were higher than patients who had not received treatment. Approximately half of the participants (48.7\%) suffered from sleep disorders and the level of depression were higher than women without sleep disorders. Patients (46.5\%) who did not have a habit of exercising suffered from a higher level of depression than women who exercised. Sleep disorders and a history of infertility treatment were associated with anxiety $(P<0.05)$.

Table 2 presents levels of depression, anxiety, infertility-related stress, self-esteem and age. The mean score of HADS-D and HADS-A were $5.35(\mathrm{SD}=4.42)$ and 7.04 $(\mathrm{SD}=3.76)$, and ranged from 0 to 16 and from 0 to 18 , respectively. The mean values were 140.41 ( $\mathrm{SD}=30.29)$ and 29.08 ( $\mathrm{SD}=3.94)$ for PFI and RSES, respectively. In addition, the prevalence of depression was $27.9 \%$ (possible depression: 20.3\%; probable depression: $7.6 \%$ ) and anxiety was $42.2 \%$ (possible anxiety: $23.5 \%$; probable anxiety: $18.7 \%$ ) for female infertility.

\section{Correlations Among Continuous Variables}

Table 3 demonstrates correlations among infertility-related stress, self-esteem and depression. Infertility-related stress was significantly and positively associated with depression and anxiety $(P<0.01)$, whereas self-esteem was significantly and negatively associated with depression and anxiety $(P<0.01)$. Age was also significantly and negatively associated with anxiety $(P<0.05)$.

\section{Hierarchical Regression Analysis}

Tables 4 and 5 shows the predictors of depression and anxiety based on hierarchical regression analysis. Based on the results of the univariate analyses, age, education, income, sleep disorders, number of times of exercise weekly and history of infertility treatment were defined as control variables in the regression model 1 of depression, and age, sleep disorders and history of infertility treatment were entered into the regression model 1 of anxiety. In model 2 , infertility-related stress was significantly and positively associated with depression $(\beta=0.339$, $P<0.001)$ and anxiety $(\beta=0.401, P<0.001)$. Self-esteem (depression: $\beta=-0.280, \quad P<0.001$; anxiety: $\beta=-0.225$, $P<0.001)$ in model 3 , together with infertility-related stress, showed $31.4 \%$ variance in depression and $31.0 \%$ in anxiety. In model 4 , interactions were significantly and negatively associated with depression $(F=29.203, \beta=$ 
Table I Distribution of Characteristics and Univariate Analyses of Depression and Anxiety

\begin{tabular}{|c|c|c|c|c|c|}
\hline \multirow[t]{2}{*}{ Variables } & \multirow[t]{2}{*}{$\mathbf{N}(\%)$} & \multirow{2}{*}{$\begin{array}{l}\text { Depression } \\
\text { Mean I SD }\end{array}$} & \multirow[t]{2}{*}{$P$} & \multirow{2}{*}{$\begin{array}{c}\text { Anxiety } \\
\text { Mean } \pm \text { SD }\end{array}$} & \multirow[t]{2}{*}{$P$} \\
\hline & & & & & \\
\hline Age & & & 0.931 & & 0.177 \\
\hline $20-29$ & $128(23.9)$ & $5.4 I \pm 3.4 I$ & & $7.42 \pm 3.96$ & \\
\hline $30-39$ & $365(68.1)$ & $5.35 \pm 3.43$ & & $7.00 \pm 3.75$ & \\
\hline$>40$ & $43(8.0)$ & $5.19 \pm 3.30$ & & $6.21 \pm 3.76$ & \\
\hline Residence & & & 0.419 & & 0.536 \\
\hline Rural area & $\mathrm{III}(20.7)$ & $5.59 \pm 3.21$ & & $7.23 \pm 3.59$ & \\
\hline Urban area & $425(79.3)$ & $5.29 \pm 3.46$ & & $6.99 \pm 3.80$ & \\
\hline Education level & & & 0.008 & & 0.395 \\
\hline Senior high school or lower & $224(41.8)$ & $5.86 \pm 3.38$ & & $7.18 \pm 3.72$ & \\
\hline Junior college & || $4(2 \mid .3)$ & $5.25 \pm 3.35$ & & $6.61 \pm 3.86$ & \\
\hline Bachelor degree or above & $198(36.9)$ & $4.83 \pm 3.4 I$ & & $7.12 \pm 3.74$ & \\
\hline Income (RMB, yuan) & & & 0.001 & & 0.413 \\
\hline$<4000$ & $144(26.9)$ & $6.19 \pm 3.29$ & & $7.26 \pm 3.62$ & \\
\hline$\geq 4000$ & $392(73.1)$ & $5.04 \pm 3.40$ & & $6.96 \pm 3.81$ & \\
\hline History of pregnancy & & & 0.616 & & 0.588 \\
\hline No & $283(52.8)$ & $5.28 \pm 3.48$ & & $6.95 \pm 3.81$ & \\
\hline Yes & $253(47.2)$ & $5.43 \pm 3.33$ & & $7.13 \pm 3.70$ & \\
\hline Cause of infertility & & & 0.116 & & 0.227 \\
\hline Female factor & $331(61.8)$ & $5.5 I \pm 3.20$ & & $7.26 \pm 3.71$ & \\
\hline Male factor & $93(17.4)$ & $4.69 \pm 3.86$ & & $6.65 \pm 4.10$ & \\
\hline Unexplained & $112(20.9)$ & $5.45 \pm 3.58$ & & $6.7 I \pm 3.60$ & \\
\hline History of infection & & & 0.535 & & 0.878 \\
\hline No & $496(92.5)$ & $5.33 \pm 3.44$ & & $7.03 \pm 3.75$ & \\
\hline Yes & $40(7.5)$ & $5.68 \pm 3.03$ & & $7.13 \pm 3.96$ & \\
\hline History of operation & & & 0.126 & & 0.141 \\
\hline No & $316(59.0)$ & $5.17 \pm 3.44$ & & $6.85 \pm 3.75$ & \\
\hline Yes & $220(41.0)$ & $5.60 \pm 3.36$ & & $7.30 \pm 3.77$ & \\
\hline History of infertility treatment & & & 0.019 & & 0.007 \\
\hline No & $22 I(4 \mid .2)$ & $4.94 \pm 3.28$ & & $6.52 \pm 3.52$ & \\
\hline Yes & $315(58.8)$ & $5.64 \pm 3.47$ & & $7.40 \pm 3.88$ & \\
\hline Negative life event & & & 0.403 & & 0.087 \\
\hline No & 404 & $5.28 \pm 3.39$ & & $6.88 \pm 3.65$ & \\
\hline Yes & 132 & $5.57 \pm 3.47$ & & $7.52 \pm 4.05$ & \\
\hline Sleep disorders & & & $<0.001$ & & $<0.001$ \\
\hline No & $275(51.3)$ & $4.50 \pm 3.23$ & & $5.86 \pm 3.46$ & \\
\hline Yes & $26 \mid(48.7)$ & $6.25 \pm 3.37$ & & $8.28 \pm 3.67$ & \\
\hline Times of exercise weekly & & & 0.006 & & 0.083 \\
\hline 0 & $249(46.5)$ & $5.86 \pm 3.44$ & & $7.42 \pm 3.82$ & \\
\hline $\mathrm{I}-2$ & $188(35.1)$ & $4.95 \pm 3.41$ & & $6.76 \pm 3.66$ & \\
\hline $3-4$ & $99(18.5)$ & $4.85 \pm 3.18$ & & $6.61 \pm 3.72$ & \\
\hline Sources of stress & & & 0.764 & & 0.095 \\
\hline The family & $166(31.0)$ & $5.25 \pm 3.48$ & & $7.17 \pm 3.66$ & \\
\hline Oneself & $293(54.7)$ & $5.34 \pm 3.37$ & & $6.77 \pm 3.81$ & \\
\hline Others (friend or colleague) & $77(14.4)$ & $5.60 \pm 3.43$ & & $7.78 \pm 69$ & \\
\hline
\end{tabular}

Abbreviation: SD, standard deviation. 
Table 2 Description Statistics for Continuous Variables

\begin{tabular}{|l|l|l|l|l|}
\hline Variables & Mean & SD & Range & n (\%) \\
\hline Age & 32.77 & 4.42 & $22-47$ & \\
\hline Depression & 5.35 & 3.41 & $0-16$ & \\
\hline $8 \leq$ Scores $\leq 10$ & & & & $109(20.3)$ \\
\hline $\mathrm{II} \leq$ Scores $\leq 21$ & & & & $41(7.6)$ \\
\hline Anxiety & 7.04 & 3.76 & $0-18$ & \\
\hline $8 \leq$ Scores $\leq 10$ & & & & $126(23.5)$ \\
\hline $\mathrm{II} \leq$ Scores $\leq 21$ & & & & $100(18.7)$ \\
\hline Infertility-related stress & $140.4 \mathrm{I}$ & 30.29 & $6 \mathrm{I}-226$ & \\
\hline Self-esteem & 29.08 & 3.94 & $17-40$ & \\
\hline
\end{tabular}

Abbreviation: SD, standard deviation.

Table 3 Correlations Among Continuous Variables

\begin{tabular}{|l|c|c|c|c|c|}
\hline Variables & $\mathbf{I}$ & $\mathbf{2}$ & $\mathbf{3}$ & $\mathbf{4}$ & $\mathbf{5}$ \\
\hline I.Age & $\mathrm{I}$ & & & & \\
2.Depression & -0.11 & $\mathrm{I}$ & & & \\
3.Anxiety & $-0.103^{*}$ & $0.66 \mathrm{I}^{* *}$ & $\mathrm{I}$ & & \\
4.Infertility- & -0.059 & $0.456^{* *}$ & $0.45 \mathrm{I}^{* *}$ & $\mathrm{I}$ & \\
related stress & & & & & \\
5. Self-esteem & $0.163^{* *}$ & $-0.444^{* *}$ & $-0.406^{* *}$ & $-0.445^{* *}$ & $\mathrm{I}$ \\
\hline
\end{tabular}

Notes: $* p<0.05, * * p<0.01$.

-0.099 , adjusted $R^{2}=0.322, P<0.001$ ), indicating that the effect of infertility-related stress on depression decreased as the self-esteem of the infertile women increased. For anxiety, the interaction term was significant in model 4
( $F=43.105, \beta=-0.133$, adjusted $\left.R^{2}=0.321, P<0.001\right)$, indicating that the effect of infertility-related stress on anxiety gradually decreased as the self-esteem of the infertile women increased.

\section{Mediating Effect of Self-Esteem}

As shown in Tables 4 and 5, infertility-related stress was positively and significantly associated with depression $(\beta=0.339, P<0.001)$ and anxiety $(\beta=0.401, P<0.001)$ in model 2. In model 3 , self-esteem was negatively correlated with depression $(\beta=-0.280, P<0.001)$ and anxiety $(\beta=$ $-0.225, P<0.001)$ and the effect of infertility-related stress on depression $(\beta=0.288, P<0.001)$ and anxiety $(\beta=0.306$, $P<0.001)$ was smaller than that in model 2, indicating that self-esteem may be a partial mediator of the relationship between infertility-related stress with depression and anxiety.

Table 6 shows that self-esteem mediated the relationship between infertility-related stress with depression $(\mathrm{a} * \mathrm{~b}=0.1109$, BCa $95 \%$ CI: $0.0770,0.1495)$ and anxiety $(a * b=0.0956$, BCa $95 \%$ CI: 0.0622,0.1327). Therefore, self-esteem was found to play a partial mediating effect on the relationship between infertility-related stress with depression $\left(c^{\prime}=0.1133, P<0.001\right)$ and anxiety $\left(c^{\prime}=0.1133\right.$, $P<0.001)$.

\section{Discussion}

In the study population, the prevalence of depression was 27.9\% (possible depression: 20.3\%; probable depression: $7.6 \%$ ) and anxiety was $42.2 \%$ (possible anxiety: $23.5 \%$; probable anxiety: $18.7 \%$ ), which revealed the significantly worse psychological status of infertile women based on depression and anxiety. In addition, the prevalence of

Table 4 Hierarchical Linear Regression Analyses of the Factors Associated with Depression

\begin{tabular}{|c|c|c|c|c|}
\hline \multirow[t]{2}{*}{ Variables } & \multicolumn{4}{|c|}{ Depression } \\
\hline & Model I $(\beta)$ & Model $2(\beta)$ & Model 3( $\beta)$ & Model 4( $\beta)$ \\
\hline Age & 0.023 & 0.036 & 0.068 & 0.064 \\
\hline Education level & -0.082 & -0.051 & -0.006 & -0.003 \\
\hline Income & $-0.134 * * *$ & $-0.093 *$ & $-0.073^{*}$ & -0.068 \\
\hline History of infertility treatment & $0.088^{*}$ & 0.057 & 0.056 & 0.053 \\
\hline Sleep disorders & $0.245^{* * *}$ & $0.188 * * *$ & $0.167 * * *$ & $0.167^{* * *}$ \\
\hline Times of exercise weekly & $-0.106^{*}$ & $-0.076^{*}$ & -0.068 & -0.069 \\
\hline Infertility-related stress & & $0.399 * * *$ & $0.288 * * *$ & $0.297^{* * *}$ \\
\hline Self-esteem & & & $-0.280 * * *$ & $-0.294 * * *$ \\
\hline Interaction & & & & $-0.099 * *$ \\
\hline$F$ & 11.574 & 27.275 & 31.547 & 29.203 \\
\hline Adjusted $R^{2}$ & 0.106 & 0.256 & 0.314 & 0.322 \\
\hline
\end{tabular}

Notes: ${ }^{*} p<0.05, * * p<0.01, * * * p<0.001$. 
Table 5 Hierarchical Linear Regression Analyses of the Factors Associated with Anxiety

\begin{tabular}{|c|c|c|c|c|}
\hline \multirow[t]{2}{*}{ Variables } & \multicolumn{4}{|c|}{ Anxiety } \\
\hline & Model I $(\beta)$ & Model 2( $\beta)$ & Model 3( $\beta)$ & Model 4( $\beta)$ \\
\hline Age & $-0.084^{*}$ & -0.064 & -0.034 & -0.039 \\
\hline History of infertility treatment & $0.102 *$ & 0.069 & 0.069 & 0.066 \\
\hline Sleep disorders & $0.312 * * *$ & $0.251 * * *$ & $0.234 * * *$ & $0.233^{* * * *}$ \\
\hline Infertility-related stress & & $0.401 * * *$ & $0.306 * * *$ & $0.315^{* * * *}$ \\
\hline Self-esteem & & & $-0.225^{* * *}$ & $-0.240 * * *$ \\
\hline Interaction & & & & $-0.133 * *$ \\
\hline$F$ & 24.411 & 50.783 & 49.011 & 43.105 \\
\hline Adjusted $R^{2}$ & 0.116 & 0.271 & 0.310 & 0.321 \\
\hline
\end{tabular}

Notes: ${ }_{p}<0.05, * * p<0.01$, $* * * * 0.001$.

comorbidity was $22.4 \%$, indicating that depression and anxiety coexist in Chinese women with infertility. This result was similar to the results of previous studies. ${ }^{22,36}$ This situation is notable because the comorbidity of depression and anxiety exhibited worse symptoms, lower compliance for treatment and poorer prognosis than patients with a single mental problem.

Additionally, compared with other studies, the prevalence of mood disorders in our study population was higher. For instance, Chiaffarino et al (2011) reported that the prevalence of depression and anxiety were $17.9 \%$ and $14.7 \%$ among women undergoing assisted reproductive treatment at an Italian infertility department in a study conducted on 1000 couples. ${ }^{12}$ Biringer et al (2015) found that $17.0 \%$ of infertile women suffered from anxiety and $7.0 \%$ from depression in study conducted in Norway on 12,584 Norwegian women from 1995 to $1997 .{ }^{37}$ In addition, Peterson et al (2014) showed that depression was reported in $11.6 \%$ of 1131 infertile women included in a study conducted in Denmark. ${ }^{38}$ In this study, the mean score of depression based on HADSD was $5.35 \pm 4.42$, which was higher than the results of the study conducted in Italy $(3.34 \pm 1.65),{ }^{39}$ and the prevalence of anxiety $(7.04 \pm 3.76)$ was similar to that of the study conducted in Iran $(8.40 \pm 4.51){ }^{40}$ The mean value of infertility-related stress measured using the FPI was $140.41 \pm 30.29$, which was similar to the results of the study conducted in France $(140.81 \pm 24.54),{ }^{41}$ and was higher than the that of the study conducted in Italy $(134.20 \pm 28.96){ }^{42}$ The average score for self-esteem based on RSES was $29.08 \pm 3.94$, which was higher than that of studies conducted in Egypt $(19.55 \pm 3.38)^{43}$ and

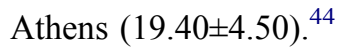

The results of univariate analyses showed that income, education, history of infertility treatment, sleep disorders and exercise were associated with an increase in the prevalence of depression and anxiety. Education was significantly associated with the development of depression, which is in line with the findings of previous studies. ${ }^{37,45}$ A higher education level was associated with a lower prevalence of depression because women with higher education may have different life roles or other social/work opportunities than only becoming mothers and having to fixate themselves on this life goal. These opportunities may allow them to accept infertility to some extent and cause less distress. A previous study also found that monthly family income was important factor that determined the level of depression. ${ }^{46}$ Family income can put an additional strain on the psychological and psychological status of couples struggling with infertility. ${ }^{47}$ Improvement

Table 6 Test of Mediation Model

\begin{tabular}{|l|c|c|c|c|c|c|c|}
\hline $\mathbf{X}$ & $\mathbf{M}$ & $\mathbf{Y}$ & $\mathbf{C}$ & $\mathbf{a}$ & $\mathbf{b}$ & $\mathbf{c}$ & $\mathbf{a} * \mathbf{b}(\mathbf{B C a} 95 \% \mathbf{C l})$ \\
\hline \multirow{2}{*}{ Infertility-related stress } & \multirow{2}{*}{ Self-esteem } & Depression & $0.3990^{* * *}$ & $-0.3962 * * *$ & $-0.2799 * * *$ & $0.288 I^{* * *}$ & $0.1109(0.0770,0.1495)$ \\
\cline { 3 - 8 } & & Anxiety & $0.4014 * * *$ & $-0.4242^{* * *}$ & $-0.2253^{* * *}$ & $0.3058^{* * *}$ & $0.0956(0.0622,0.1327)$ \\
\hline
\end{tabular}

Notes: $* * * p<0.001 .{ }^{a}$ Assozciations of infertility-related stress with self-esteem. ${ }^{b}$ Associations of self-esteem with depression or anxiety. ${ }^{\mathrm{c}}$ Direct associations of infertilityrelated stress with depression or anxiety. ${ }^{\prime}$ 'Indirect associations of infertility-related stress with depression or anxiety. BCa $95 \% \mathrm{Cl}$ : Bias-corrected and accelerated $95 \%$ Confidence Interval. Age, education level, income, history of infertility treatment, sleep disorders and times of exercise weekly are covariates for depression. Age, history of infertility treatment, sleep disorders are covariates for anxiety. 
in educational level and family income may increase feelings of control and self-confidence in female infertility patients, which relieved their level of depression to some extent. Several articles have reported that (unsuccessful) infertility treatment increases the probability of negative emotions, ${ }^{48}$ especially for depression and anxiety. ${ }^{46}$ Patients with a higher income had lower scores of depressions in our study. Additionally, a recent study found that poor sleep quality contributed to the development of depression and anxiety in infertile women undergoing in vitro fertilization treatment. ${ }^{49}$

Overall, the results of this study showed that after adjusting for control variables, infertility-related stress was an important factor that affected the prevalence of mood disorders in infertile women. More specifically, infertility-related stress was significantly and positively associated with depression and anxiety, which is in accordance with several previous studies. A diagnosis of infertility acts as a negative stressor that increases feelings of stigma and guilt, inducing a series of negative emotions. The stress-health theory suggests that high levels of stress experienced over a long duration could damage an individual's immune system, and may even lead to psychological and physical vulnerability. ${ }^{50}$ Other studies concerning infertility in women have reported that infertility-related stress exhibited a significant effect on psychological distress (eg, depression and anxiety). ${ }^{18,19}$ Additionally, infertility-related stress can decrease individual well-being and increase marital conflicts. ${ }^{41,51}$ Noticeably, the mean score of infertility-related stress in our study was higher than that of studies conducted in other countries. ${ }^{52,53}$ A possible interpretation of this difference may be due to differences in traditional culture. In China, couples are more inclined to give priority to the needs of family members (eg, having babies) over their own interest, and individuals without children are socially marginalized. Therefore, female infertility may be more vulnerable to comments regarding childlessness, and easily induce uncomfortable feelings, resulting in an increase of mental health problems.

An increasing number of scholars have become interested in the effects of positive psychological resources on mental health outcomes. Our research study took this research direction to analyze the integrative and independent contributions of these positive psychological effects on depression in a heterogeneous sample of female infertility patients. Self-esteem accounted for a mediating proportion of variance of depression (27.8\%) and anxiety (23.8\%). Self-esteem, an important inner resource needed for proper psychological and social functioning, was found to be negatively correlated with depression and anxiety, which were consistent with the findings of previous studies. $^{22,23}$ Moreover, self-esteem was independently associated with infertility-related stress, indicating that each form of positive expectations had an unique association with infertility-related stress. These results contributed to the understanding that self-esteem was a positive resource for combating mental health problems and encouraged us to explore the mediating role of positive psychological resources on the relationship between infertility-related stress with depression and anxiety in this population.

In this study, self-esteem played a partial mediating role in the relationship between infertility-related stress with depression and anxiety. In other words, women with fertility who perceived more infertile-related stress were more likely to experience lower levels of positive psychological resources, which in turn increased their possibility of developing depression. Compared with decreasing levels of infertility-related stress, a more positive and strategic method of treatment is to develop programs that increase the inner positive resources of patients, thus enhancing their mental health in the long run. Additionally, our study found that self-esteem moderated the effect of infertility-related stress on depression and anxiety in infertile females. Simple slope analysis showed that when fertile women possessed a high level of selfesteem, levels of depression and anxiety decreased significantly along with high levels of infertility-related stress, compared with low levels of infertility-related stress. In other words, women with fertility possess a high level of self-esteem, and can better maintain mental health even at a higher level of infertility-related stress. Therefore, resilience on self-esteem should be emphasized and developed for individuals to be able to cope with mental health problems.

\section{Implications}

According to our findings, some valuable implications of this study that will allow for individuals to cope with psychological distress and improve mental health nursing for infertile women should be highlighted. First, there is an urgent need to evaluate patient psychological status during diagnosis and treatment for infertility. Second, psychological counseling should be integrated into in vitro fertilization treatment and other treatment methods to help infertile women cope with mental health problems. 
Third, family is one of the main sources of stress, and thus, especially spouses should be provided with information on how to be supportive and understanding during mental nursing, which can relieve the negative mood of patients. Finally, self-esteem can mediate and moderate the effects of infertility-related stress on depression and anxiety, as shown in the current study. Therefore, self-esteem is an important positive psychological resource that can reduce stress and improve the mental health of infertile women. Psychological interventions that aim to increase selfesteem should be introduced by clinicians and nurses for women with infertility. Since the building of self-esteem is usually regarded as a dynamic process, interventions such as cognitive-behavioral therapy and mindfulness-based skills can be introduced to infertile women to increase their level of self-esteem, thereby improve mental health. Therefore, targeted intervention approaches should be tested in the next study.

\section{Limitations}

There are several limitations in this current study. First, our study was of a cross-sectional design. Longitudinal studies are required to replicate our results in further research. Second, these associations in our study may be underestimated or overestimated due to the study being based on selfreported measurement tools. Third, the present study only recruited a non-random sample of infertile women from Liaoning province, which may result in self-selection bias among participants, and limit the generalizability of findings in our study. Finally, the results of our study may be overrated due to the small sample size and high data fluctuations. Furthermore, research conducted in high-income or developed countries showed a lower level of depression and anxiety compared with developing or low-income countries, such as China. People in developed or higher income countries tend to possess adequate health resources and better health literacy to deal with mental health problems.

\section{Conclusions}

In summary, our findings revealed that Chinese infertile women had a high prevalence of depression and anxiety. Self-esteem was negatively associated with depression and anxiety. Additionally, self-esteem could affect the effects of infertility-related stress on depression and anxiety. Specifically, self-esteem mediated and moderated the effects of infertility-related stress on depression and anxiety. In addition, infertility-related stress was positively associated with depression and anxiety among Chinese female infertility patients. Thus, interventions that can decrease infertility-related stress and enhance levels of self-esteem should be developed and put applied on Chinese women with infertility.

\section{Data Sharing Statement}

The dataset in this study is available from the corresponding author on reasonable request.

\section{Ethics Approval and Informed Consent}

The study was approved by the Ethics Committee on Human Experimentation of China Medical University, and the study procedures were in accordance with ethical standards. All patients provided their written informed consent prior to responding to the survey The study was in accordance with Declaration of Helsinki.

\section{Acknowledgment}

We would like to thank all the patients who voluntarily participated in this study and research assistants who performed the data collection.

\section{Author Contributions}

All authors made substantial contributions to conception and design, acquisition of data, or analysis and interpretation of data; took part in drafting the article or revising it critically for important intellectual content; agreed to submit to the current journal; gave final approval of the version to be published; and agree to be accountable for all aspects of the work.

\section{Funding}

There was no funding support.

\section{Disclosure}

The authors report no conflicts of interest for this work.

\section{References}

1. Zegers-Hochschild F, Adamson GD, de Mouzon J, et al. International committee for monitoring assisted reproductive technology; world health organization. international committee for monitoring assisted reproductive technology (ICMART) and the World Health Organization (WHO) revised glossary of ART terminology, 2009. Fertil Steril. 2009;92(5):1520-1524. doi:10.1016/j. fertnstert.2009.09.009

2. Maroufizadeh S, Ghaheri A, Almasi-Hashiani A, et al. The prevalence of anxiety and depression among people with infertility referring to Royan Institute in Tehran, Iran: a cross-sectional questionnaire study. Middle East Fertil Soc J. 2018;23(2):103-106. doi:10.1016/j. mefs.2017.09.003 
3. Polis CB, Cox CM, Tunçalp Ö, McLain AC, Thoma ME. Estimating infertility prevalence in low-to-middle-income countries: an application of a current duration approach to demographic and health survey data. Hum Reprod. 2017;32(5):1064-1074. doi:10.1093/humrep/ $\operatorname{dex} 025$

4. Mascarenhas MN, Flaxman SR, Boerma T, Vanderpoel S, Stevens GA. National, regional, and global trends in infertility prevalence since 1990: a systematic analysis of 277 health surveys. PLoS Med. 2012;9(12):e1001356. doi:10.1371/journal.pmed.1001356

5. Zhou Z, Zheng D, Wu H, et al. Epidemiology of infertility in China: a population-based study. BJOG. 2018;125(4):432-441. doi:10.1111/ 1471-0528.14966

6. Liu J, Larsen U, Wyshak G. Prevalence of primary infertility in China: in-depth analysis of infertility differentials in three minority province/autonomous regions. J Biosoc Sci. 2005;37(1):55-74. doi: $10.1017 / \mathrm{s} 0021932003006461$

7. Junqing W, Qiuying Y, Jianguo T, et al. Reference value of semen quality in Chinese young men. Contraception. 2002;65(5):365-368. doi:10.1016/s0010-7824(02)00281-0

8. Reis S, Xavier MR, Coelho R, Montenegro N. Psychological impact of single and multiple courses of assisted reproductive treatments in couples: a comparative study. Eur J Obstet Gynecol Reprod Biol. 2013;171(1):61-66. doi:10.1016/j.ejogrb.2013.07.034

9. Schaller MA, Griesinger G, Banz-Jansen C. Women show a higher level of anxiety during IVF treatment than men and hold different concerns: a cohort study. Arch Gynecol Obstet. 2016;293 (5):1137-1145. doi:10.1007/s00404-016-4033-x

10. Schmidt L. Social and psychological consequences of infertility and assisted reproduction - what are the research priorities? Hum Fertil. 2009;12(1):14-20. doi:10.1080/14647270802331487

11. Covington SN, ed. Fertility Counseling: Clinical Guide and Case Studies. Cambridge, England: Cambridge University Press; 2015.

12. Chiaffarino F, Baldini MP, Scarduelli C, et al. Prevalence and incidence of depressive and anxious symptoms in couples undergoing assisted reproductive treatment in an Italian infertility department. Eur J Obstet Gynecol Reprod Biol. 2011;158(2):235-241. doi:10.1016/j.ejogrb.2011.04.032

13. Williams KE, Marsh WK, Rasgon NL. Mood disorders and fertility in women: a critical review of the literature and implications for future research. Hum Reprod Update. 2007;13(6):607-616. doi:10.1093/humupd/dmm019

14. Chen TH, Chang SP, Tsai CF, Juang KD. Prevalence of depressive and anxiety disorders in an assisted reproductive technique clinic. Hum Reprod. 2004;19(10):2313-2318. doi:10.1093/humrep/deh414

15. Volgsten H, Ekselius L, Poromaa IS, Svanberg AS. Personality traits associated with depressive and anxiety disorders in infertile women and men undergoing in vitro fertilization treatment. Acta Obstet Gynecol Scand. 2010;89(1):27-34. doi:10.3109/00016340903447396

16. Wilson JF, Kopitzke EJ. Stress and infertility. Curr Women's' Hlth Rep. 2002;2:194-199.

17. Milazzo A, Mnatzaganian G, Elshaug AG, Hemphill SA, Hiller JE; Astute Health Study Group. Depression and anxiety outcomes associated with failed assisted reproductive technologies: a systematic review and meta-analysis. PLoS One. 2016;11(11):e0165805. doi:10.1371/journal.pone. 0165805

18. Chaves C, Canavarro MC, Moura-Ramos M. The Role of dyadic coping on the marital and emotional adjustment of couples with infertility. Fam Process. 2019;58(2):509-523. doi:10.1111/ famp. 12364

19. Zurlo MC, Cattaneo Della Volta MF, Vallone F. Factor structure and psychometric properties of the Fertility Problem Inventory-Short Form. Health Psychol Open. 2017;4(2):2055102917738657. doi: $10.1177 / 2055102917738657$

20. Newton CR, Sherrard W, Glavac I. The Fertility Problem Inventory: measuring perceived infertility-related stress. Fertil Steril. 1999;72 (1):54-62. doi:10.1016/S0015-0282(99)00164-8
21. Sharma S, Agarwala S. Self-esteem and collective self-esteem as predictors of depression. J Behav Sci. 2014;24:1.

22. El Kissi Y, Romdhane AB, Hidar S, et al. General psychopathology, anxiety, depression and self-esteem in couples undergoing infertility treatment: a comparative study between men and women. Eur J Obstet Gynecol Reprod Biol. 2013;167(2):185-189. doi:10.1016/j. ejogrb.2012.12.014

23. Zayed AA, El-Hadidy MA. Sexual satisfaction and self-esteem in women with primary infertility. Middle East Fertility Society J. 2020;25:1. doi:10.1186/s43043-020-00024-5

24. Bajaj B, Robins RW, Pande N. Mediating role of self-esteem on the relationship between mindfulness, anxiety, and depression. Personality Individual Differences. 2016;96:127-131. doi:10.1016/j. paid.2016.02.085

25. Brunet J, Pila E, Solomon-Krakus S, Sabiston CM, O’Loughlin J. Self-esteem moderates the associations between body-related self-conscious emotions and depressive symptoms. $J$ Health Psychol. 2019;24(6):833-843. doi:10.1177/1359105316683786

26. Men XL, Li DF, Wang RK, Zhao LP. Analysis of mental health status and influencing factors of female infertility patients. China Modern Med. 2020;27:36.

27. Zigmond AS, Snaith RP. The hospital anxiety and depression scale. Acta Psychiatr Scand. 1983;67(6):361-370. doi:10.1111/acp.1983.67.issue-6

28. Yang Z, Huang X, Liu X, et al. Psychometric properties and factor structure of the chinese version of the hospital anxiety and depression scale in people living with HIV. Front Psychiatry. 2019;10:346. doi:10.3389/fpsyt.2019.00346

29. Peng T, Coates R, Merriman G, Zhao Y, Maycock B. Testing the psychometric properties of Mandarin version of the fertility problem inventory (M-FPI) in an infertile Chinese sample. J Psychosom Obstet Gynaecol. 2011;32(4):173-181. doi:10.3109/0167482X.2011.609950

30. Rosenberg M. Society and the Adolescent Self-Image. Sociology. $1965 ; 2: 458$.

31. Cheng ST, Hamid PN. An error in the use of translated scales: the rosenberg self-esteem scale for Chinese. Perceptual Motor Skills. 1995;81(2):431-434. doi:10.3758/BF03205466

32. Urzúa A, Ferrer R, Godoy N, et al. The mediating effect of self-esteem on the relationship between perceived discrimination and psychological well-being in immigrants. PLoS One. 2018;13(6): e0198413. doi:10.1371/journal.pone.0198413

33. Chen FF. The reliability and validity of the chinese version of the revised-positive version of rosenberg self-esteem scale. Adv Psychol. 2015;05(9):531-535. doi:10.12677/AP.2015.59068

34. Hayes A. Introduction to mediation, moderation, and conditional process analysis. $J$ Edu Measurement. 2013;51(3):335-337.

35. Preacher KJ, Hayes AF. Asymptotic and resampling strategies for assessing and comparing indirect effects in multiple mediator models. Behav Res Methods. 2008;40(3):879-891. doi:10.3758/brm.40.3.879

36. Tola EN, Eris Yalcin S, Dugan N, Oral B. The association of type D personality and depression with infertility in women. $J$ Psychosom Obstet Gynaecol. 2020;41(2):98-105. doi:10.1080/ 0167482X.2019.1573224

37. Biringer E, Howard LM, Kessler U, Stewart R, Mykletun A. Is infertility really associated with higher levels of mental distress in the female population? Results from the north-trøndelag health study and the medical birth registry of Norway. J Psychosom Obstet Gynaecol. 2015;36(2):38-45. doi:10.3109/0167482X.2014.992411

38. Peterson BD, Sejbaek CS, Pirritano M, Schmidt L. Are severe depressive symptoms associated with infertility-related distress in individuals and their partners? Hum Reprod. 2014;29(1):76-82. doi:10.1093/humrep/det412

39. Massarotti C, Gentile G, Ferreccio C, Scaruffi P, Remorgida V, Anserini P. Impact of infertility and infertility treatments on quality of life and levels of anxiety and depression in women undergoing in vitro fertilization. Gynecol Endocrinol. 2019;35(6):485-489. doi:10.1080/09513590.2018.1540575 
40. Maroufizadeh S, Karimi E, Vesali S, Omani Samani R. Anxiety and depression after failure of assisted reproductive treatment among patients experiencing infertility. Int J Gynaecol Obstet. 2015;130 (3):253-256. doi:10.1016/j.ijgo.2015.03.044

41. Gana K, Jakubowska S. Relationship between infertility-related stress and emotional distress and marital satisfaction. J Health Psychol. 2016;21(6):1043-1054. doi:10.1177/1359105314544990

42. Donarelli Z, Gullo S, Lo Coco G, et al. Assessing infertility-related stress: the factor structure of the Fertility Problem Inventory in Italian couples undergoing infertility treatment. $J$ Psychosom Obstet Gynaecol. 2015;36(2):58-65. doi:10.3109/0167482X.2015.1034268

43. Schover LR. Sexuality and body image in younger women with breast cancer. J Natl Cancer Inst Monogr. 1994;2(16):177-182.

44. Ruth A, Akintayo A. Comparison of self-esteem and depression among fertile and infertile women. BJPsych Open. 2021;7(1):S48S48. doi:10.1192/bjo.2021.176

45. Ramezanzadeh F, Aghssa MM, Abedinia N, et al. A survey of relationship between anxiety, depression and duration of infertility. BMC Womens Health. 2004;4(1):9. doi:10.1186/1472-6874-4-9

46. Cousineau TM, Domar AD. Psychological impacts of infertility among married women attending in a tertiary hospital, Dhaka. Anwer Khan Modern Med College J. 2018;9(1):10-14. doi:10.3329/ akmmcj.v9i1.35817

47. Akyuz A, Sever N. Reasons for infertile couples to discontinue in vitro fertilization (IVF) treatment. J Reprod Infant Psychol. 2009;27(3):258-268. doi:10.1080/02646830802409652
48. Verhaak CM, Smeenk JM, Evers AW, Kremer JA, Kraaimaat FW, Braat DD. Women's emotional adjustment to IVF: a systematic review of 25 years of research. Hum Reprod Update. 2007;13 (1):27-36. doi:10.1093/humupd/dml040

49. Cui Y, Li D, Zhou B, Lin Y, Zeng Y. Mediating role of social support between sleep quality, anxiety and depressive symptoms in Chinese women undergoing in vitro fertilization treatment. SAGE Open Med. 2020;8:2050312120930163. doi:10.1177/2050312120930163

50. Segerstrom SC, Miller GE. Psychological stress and the human immune system: a meta-analytic study of 30 years of inquiry. Psychol Bull. 2004;130(4):601-630. doi:10.1037/0033-2909.130.4.601

51. Li X, Wang K, Huo Y, Zhou M. The effect of infertility-related stress on Chinese infertile females' mental health: the moderating role of marital adjustment. Psych J. 2019;8(2):232-239. doi:10.1002/ pchj. 255

52. Donarelli Z, Lo Coco G, Gullo S, et al. Infertility-related stress, anxiety and ovarian stimulation: can couples be reassured about the effects of psychological factors on biological responses to assisted reproductive technology? Reprod Biomed Soc Online. 2016;3:16-23. doi:10.1016/j.rbms.2016.10.001

53. Pedro J, Sobral MP, Mesquita-Guimarães J, Leal C, Costa ME, Martins MV. Couples' discontinuation of fertility treatments: a longitudinal study on demographic, biomedical, and psychosocial risk factors. $J$ Assist Reprod Genet. 2017;34(2):217-224. doi:10.1007/s10815-016-0844-8
Psychology Research and Behavior Management

\section{Publish your work in this journal}

Psychology Research and Behavior Management is an international, peer-reviewed, open access journal focusing on the science of psychology and its application in behavior management to develop improved outcomes in the clinical, educational, sports and business arenas. Specific topics covered in the journal include: Neuroscience, memory and decision making; Behavior modification and management; Clinical

\section{Dovepress}

applications; Business and sports performance management; Social and developmental studies; Animal studies. The manuscript management system is completely online and includes a very quick and fair peer-review system, which is all easy to use. Visit http://www. dovepress.com/testimonials.php to read real quotes from published authors. 